\title{
Compositing climate change vulnerability of a Mediterranean region using spatiotemporally dynamic proxies for ecological and socioeconomic impacts and stabilities
}

\author{
Ali Can Demirkesen • Fatih Evrendilek
}

Received: 29 September 2016 / Accepted: 13 December 2016/Published online: 21 December 2016

(C) Springer International Publishing Switzerland 2016

\begin{abstract}
The study presents a new methodology to quantify spatiotemporal dynamics of climate change vulnerability at a regional scale adopting a new conceptual model of vulnerability as a function of climate change impacts, ecological stability, and socioeconomic stability. Spatiotemporal trends of equally weighted proxy variables for the three vulnerability components were generated to develop a composite climate change vulnerability index (CCVI) for a Mediterranean region of Turkey combining Landsat time series data, digital elevation model (DEM)-derived data, ordinary kriging, and geographical information system. Climate change impact was based on spatiotemporal trends of August land surface temperature (LST) between 1987 and 2016. Ecological stability was based on DEM, slope, aspect, and spatiotemporal trends of normalized difference vegetation index (NDVI), while socioeconomic stability was quantified as a function of spatiotemporal trends of land cover, population density, per capita gross domestic product, and illiteracy. The zones ranked on the five classes of no-to-extreme vulnerability were identified where highly and moderately vulnerable lands covered $0.02 \%\left(12 \mathrm{~km}^{2}\right)$ and $11.8 \%\left(6374 \mathrm{~km}^{2}\right)$ of the study
\end{abstract}

\footnotetext{
A. C. Demirkesen

Department of City and Regional Planning, Faculty of

Architecture, Izmir Institute of Technology, Izmir, Turkey

F. Evrendilek $(\bowtie)$

Department of Environmental Engineering, Faculty of Engineering and Architecture, Abant Izzet Baysal University, Bolu, Turkey

e-mail: fevrendilek@ibu.edu.tr
}

region, respectively, mostly occurring in the interior central part. The adoption of this composite CCVI approach is expected to lead to spatiotemporally dynamic policy recommendations towards sustainability and tailor preventive and mitigative measures to locally specific characteristics of coupled ecological-socioeconomic systems.

Keywords Spatiotemporal trends · Vulnerability hotspots $\cdot$ Sustainability . Time series data .

Environmental monitoring

\section{Introduction}

Globally, atmospheric carbon dioxide $\left(\mathrm{CO}_{2}\right)$ concentration varied between 180 and 300 ppm by volume (ppmv) over the last 800,000 years and now is at an unprecedented level of 402 ppmv according to the National Ocean and Atmospheric Administration (NOAA) Mauna Loa Observatory (http://www.esrl.noaa.gov/gmd/ccgg/trends/) (NRC 2010). The increase in mean global air temperature associated with the increasing concentrations of atmospheric $\mathrm{CO}_{2}$ has been by 0.72 to $1.06{ }^{\circ} \mathrm{C}$ since its preindustrial level and is projected to be by 1.67 to $2.78{ }^{\circ} \mathrm{C}$ (at $\sim 550 \mathrm{ppmv}$ ) and by 2.78 to $5.56{ }^{\circ} \mathrm{C}$ (at $\sim 625$ and 850 ppmv) for lower and higher emission scenarios, respectively (IPCC 2013). Individual impacts of global climate change include and are not limited to $\mathrm{CO}_{2}$ fertilization, increased temperature, extreme events (e.g., drought, flooding, and storm), sea level rise, altered biogeochemical cycles, and shifting spatiotemporal dynamics of ecosystem structure and function 
(Allan and Soden 2008; Diffenbaugh et al. 2013). Not only these individual effects but also their interaction effects differ spatiotemporally depending on climate change vulnerability of coupled ecological-socioeconomic systems (Wali et al. 1999; Rogelj et al. 2012).

The concept of climate change vulnerability and its three determinants (exposure, sensitivity, and adaptive capacity) for the selection of assessment indicators were first proposed by the Intergovernmental Panel on Climate Change (IPCC) Third Assessment Report (IPCC 2001) and implemented by the IPCC Fourth Assessment Report (IPCC 2007). Climate change vulnerability can be defined as the degree to which a coupled ecologicalsocioeconomic system can secure its stability against (its resilience and resistance to) negative interaction effects of climate change (Williamson et al. 2008; Evrendilek et al. 2011; Young et al. 2015). Climate change vulnerability is a dynamic ecosystem state that spatiotemporally changes in response not only to the regime (nature, magnitude, frequency, and severity) of climate change impacts but also to the degree of ecological and socioeconomic stabilities (Evrendilek et al. 2011; Birkmann et al. 2013). Ecological and socioeconomic stabilities are used here to refer to the coupled ecological and socioeconomic capacity to cope with and mitigate climate change impacts. Climate change vulnerability of a coupled ecological-socioeconomic system is anticipated to increase to the extent which the ecosystem is not ecologically and socioeconomically resilient and resistant (stable) to climate change impacts when exposed to those impacts. Ecological and socioeconomic stabilities can be quantified using ecological, demographic, economic, social, institutional, technological, and management proxy variables. Quantification and identification of climate change vulnerability are vital to setting priorities, allocating resources, identifying hotspots of climate change vulnerability, preparedness, coping with anthropogenic drivers of climate change, and enhancing mitigative capacities, in particular, at locations where immediate interventions may be required.

Remote sensing (RS) and geographical information system (GIS) technologies have emerged as the tools for monitoring terrestrial and aquatic ecosystems over time and space with little cost and effort. There exist various assessment studies that have attempted to characterize vulnerability combining both social and ecological indicators and RS data at different spatiotemporal scales in related literature (Füssel and Klein 2006; Ostrom 2009; Brondizio et al. 2016; Sebesvari et al. 2016). For example,
Bai et al. (2014) combined GIS, climate change projections, and observed socioeconomic data on a regional scale in order to characterize vulnerability as a function of its underlying components of exposure, sensitivity, and adaptive capacity in order to assist in decision-making and stakeholders. Murthy et al. (2015) computed agricultural drought vulnerability index in India using 11 ecological indicators of the same vulnerability components and moderate-resolution imaging spectroradiometer (MODIS) data between 2001 and 2012. Liu et al. (2013) assessed drought vulnerability of a coupled social-natural system in China using Satellite for Observation of Earth (SPOT)derived normalized difference vegetation index (NDVI) (1998-2008), digital elevation model (DEM), precipitation and temperature data, and socioeconomic data. Ahsan and Warner (2014) developed socioeconomic vulnerability index in coastal Bangladesh using a total of weighted 27 indicators of the same components. Young et al. (2015) developed a tool called the NatureServe Climate Change Vulnerability Index (CCVI) that has been widely used in North America to assess vulnerability of aquatic and terrestrial plant and animal species to climate change.

Although the selection of appropriate and readily available indicators for the social, institutional, economic, or ecological components of a given ecosystem changes depending on individual studies in related literature, the major common issues with such vulnerability assessments include the uses of spatiotemporally static versus dynamic factors and species versus ecosystem scale. Therefore, there is still an urgent need to fill in the knowledge gaps about how to quantify a spatiotemporally dynamic CCVI for coupled ecological-socioeconomic systems in reproducible and generalizable ways. Following this logic, the objective of the study was to quantify spatiotemporal dynamics of climate change vulnerability of a highly complex Mediterranean region over the period of 1987 to 2016 by integrating RS data, GIS techniques, and trends of nine socioeconomic and ecological proxy variables into a new composite CCVI.

\section{Materials and methods}

\section{Study region}

The study region is located between $36^{\circ}$ to $39^{\circ} \mathrm{N}$ latitudes and $29^{\circ}$ to $33^{\circ} \mathrm{E}$ longitudes and covers a total area of $68,452 \mathrm{~km}^{2}$, with its terrestrial and sea components of 
54,188 and $14,264 \mathrm{~km}^{2}$, respectively, at an elevation range from sea level to $3067 \mathrm{~m}$ above sea level (asl), the highest peak of Mountain Kizlar Sivrisi (Antalya) of the western Taurus mountain range running parallel to the Mediterranean coast (Fig. 1). The administrative units of the study region include 9 provinces and 59 districts. Approximately, 9.69 million people (12.3\% of the national population) dwelled in the study region with population density and population growth rate of 128 people $\mathrm{km}^{-2}$ and $0.67 \%$ in 2015 , compared to the nationally corresponding values of 102 people $\mathrm{km}^{-2}$ and $0.71 \%$ in 2015, respectively (TSI 2015). The study region experiences a Mediterranean climate with long, dry summers and short rainy seasons during the autumn and winter characterized by 300 to $1200 \mathrm{~mm}$ of annual rainfall or precipitation. According to long-term
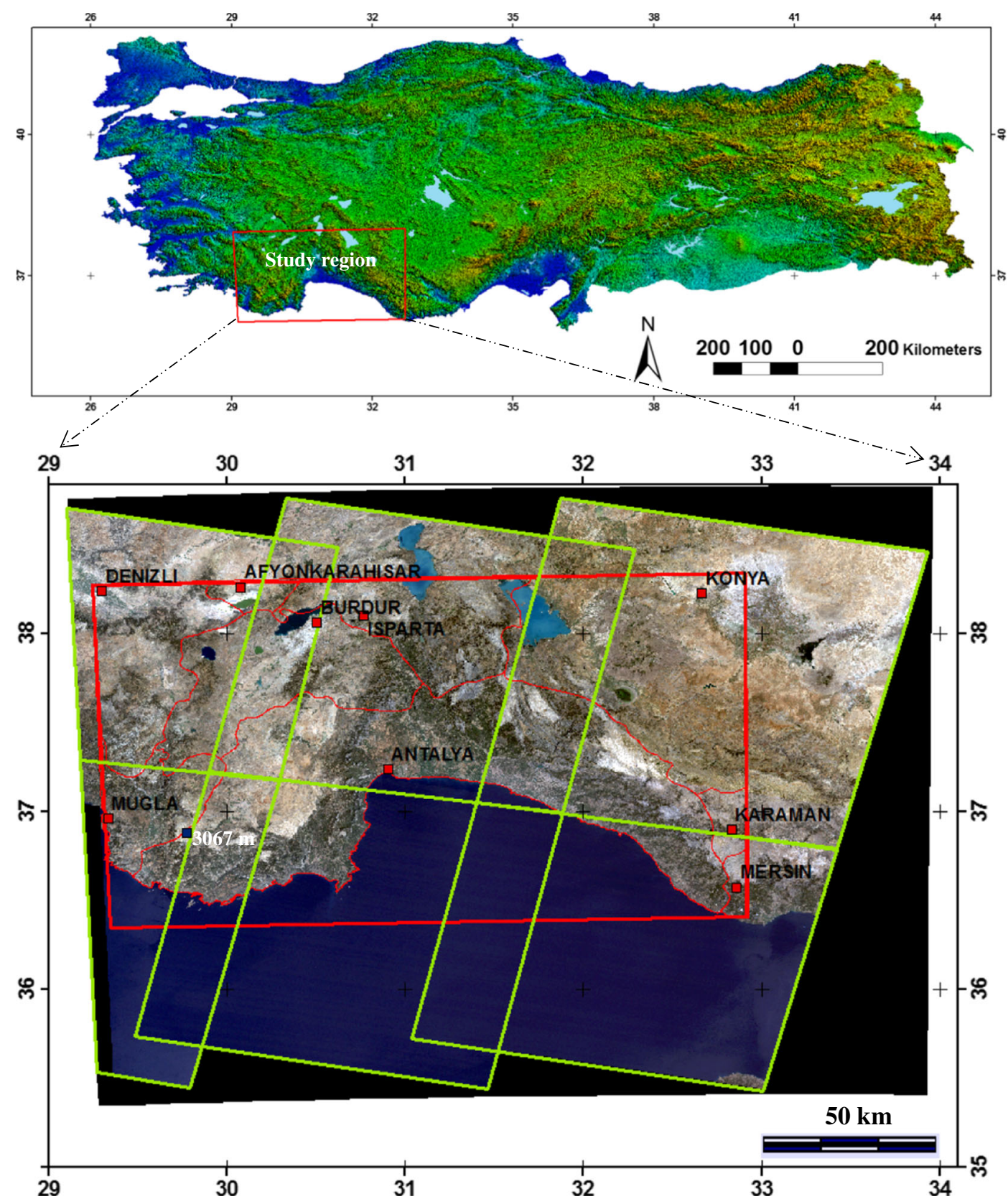

Fig. 1 Geographical location, altitudinal range, and provincial administrative divisions of the study region (in red) with the six frames of Landsat images (in green) 
meteorological data (1968-2013) from 44 stations (TSMS 2013), mean annual values across the study region ranged from $-4{ }^{\circ} \mathrm{C}$ for minimum air temperature to $30.6{ }^{\circ} \mathrm{C}$ for maximum air temperature, from 5.4 to $8.5 \mathrm{~h}$ for sunshine duration, from 10.5 to 17.5 $\mathrm{MJ} \mathrm{m}^{-2}$ day $^{-1}$ for solar radiation, from 17.9 to. $97.5 \%$ for relative humidity, and from 988 to $2190 \mathrm{~mm}$ for potential evapotranspiration.

\section{Climate change vulnerability index}

A new composite CCVI was developed in this study following the sequential three stages: (1) selection of real-time proxy variables and detection of their spatiotemporal trends, (2) normalization of the proxy variables to a common scale, and (3) raster overlay analysis. First, real-time proxy variables and their trends were identified taking into account (1) and spatiotemporally dynamic data availability and (2) the underlying conceptual components of vulnerability: (1) climate change impacts, (2) ecological stability, and (3) socioeconomic stability (Table 1). Climate change impact was represented as spatiotemporal trends of August land surface temperature (LST) between 1987 and 2016. Ecological stability of the study region was characterized using the following four proxy variables that were remotely sensed: (1) DEM, (2) slope, (3) aspect, and (4) spatiotemporal trends of NDVI between 1987 and 2016. Socioeconomic stability of the study region was quantified detecting spatiotemporal trends of the following four proxy variables: (1) population density (number of people $\mathrm{km}^{-2}$ ) between 1990 and 2015 , (2) illiteracy level (number of illiterate people) between 2009 and 2015, (3) gross domestic product (GDP) per capita (USD person ${ }^{-1}$ ) between 1987 and 2011, and (4) RS land cover (LC) $\left(\mathrm{km}^{2}\right)$ between 1987 and 2016. The census time series data (population density, illiteracy level, and GDP per capita) were sourced from the Turkish Statistical Institute (TSI) and were converted to the continuous surfaces using the interpolation method of ordinary kriging. Both remotely sensed and interpolated time series data instead of using single-time continuous surfaces of the real-time proxy variables were used to detect and integrate spatiotemporal trends of proxy variables into the composite CCVI development. Negative and positive values obtained from the subtraction between the recent and past images indicated decreasing and increasing trends of the proxy variables, respectively.

Second, weights were assigned neither to the three vulnerability components of climate change impact, ecological stability, and socioeconomic stability nor to their proxy variables in order to minimize subjectivity. The spatiotemporally dynamic and static trends of the equally weighted nine proxy variables were reclassified and normalized assigning the discrete integer values from 0 to 4 to the pixels as follows: $0=$ not vulnerable, $1=$ less vulnerable, $2=$ moderately vulnerable, $3=$ highly vulnerable, and $4=$ extremely vulnerable (Table 1 ). In so doing, the statistical distributions of pixel values and their clusters inherent within the individual proxy variables were explored to identify natural class breaks that group similar values using the graphical tool of histogram equalization.

Finally, a raster overlay analysis was carried out by which the normalized values of the individual maps were aggregated per pixel so as to form the composite CCVI values that range from 0 to 20 for not vulnerable, $>20-40$ for less vulnerable, $>40-60$ for moderately vulnerable, and $>60-80$ for highly vulnerable to $>80-100$ for extremely vulnerable (Table 1).

Processing of remotely sensed data and interpolations

Climate change impact was represented as spatiotemporal trends of August LST between 1987 and 2016 derived from the two Landsat images: Landsat 5 Thematic Mapper (TM) in 1987 and Landsat 8 Operational Land Imager (OLI) and Thermal Infrared Sensor (TIRS) in 2016. Landsat 5 and 8 data have temporal and spatial resolutions of a 16-day revisit cycle and $30 \mathrm{~m}$, and 6 and 11 multispectral bands of 0.45 to 12.5 and 0.43 to $12.51 \mu \mathrm{m}$, respectively. The Landsat sensors were preferred in this study over others owing to its long-term time series data archive provided freely by the United States Geological Survey (http://earthexplorer.usgs.gov/). Six frames $($ paths $/$ rows $=177-178-179 / 33-34$ ) were obtained for each of the Landsat $5 \mathrm{TM}$ and Landsat 8 OLI and TIRS images to cover the entire study region. The Level 1 Terrain-corrected (L1T) Landsat 5 TM and Landsat 8 OLI and TIRS images included atmospheric correction, georectification, and georeferencing to the Universal Transverse Mercator (UTM) projection system (WGS84 datum, Zone $36 \mathrm{~N}$ ). The Landsat 5 and 8 data were acquired 
Table 1 Nine proxy variables and three vulnerability components of composite climate change vulnerability index (CCVI) used in this study

\begin{tabular}{|c|c|c|c|c|c|c|c|}
\hline Index & $\begin{array}{l}\text { Proxy } \\
\text { variable }\end{array}$ & Unit & Year & Source & $\begin{array}{l}\text { Ranges and trends of } \\
\text { spatiotemporal change }\end{array}$ & $\begin{array}{l}\text { Class } \\
\text { value }\end{array}$ & $\begin{array}{l}\text { CCVI } \\
\text { value }\end{array}$ \\
\hline \multirow[t]{5}{*}{ Impact } & \multirow[t]{5}{*}{ LST } & \multirow[t]{5}{*}{${ }^{\circ} \mathrm{C}$} & \multirow{5}{*}{$\begin{array}{r}1987- \\
2016\end{array}$} & \multirow{5}{*}{ Landsat 5 and 8} & $<-20$ & 2 & $40-60$ \\
\hline & & & & & -20 to -10 & 1 & $20-40$ \\
\hline & & & & & -10 to 10 & 0 & $0-20$ \\
\hline & & & & & 10 to 20 & 3 & $60-80$ \\
\hline & & & & & $>20$ & 4 & $80-100$ \\
\hline \multirow{20}{*}{$\begin{array}{r}\text { Ecological } \\
\text { stability }\end{array}$} & \multirow[t]{5}{*}{ DEM } & \multirow[t]{5}{*}{$\mathrm{m}$} & \multirow[t]{5}{*}{2016} & \multirow[t]{5}{*}{ ASTER } & $0-500$ & 4 & $80-100$ \\
\hline & & & & & $500-1000$ & 3 & $60-80$ \\
\hline & & & & & $1000-1500$ & 2 & $40-60$ \\
\hline & & & & & $1500-2000$ & 1 & $20-40$ \\
\hline & & & & & $>2000$ & 0 & $0-20$ \\
\hline & \multirow[t]{5}{*}{ Slope } & \multirow[t]{5}{*}{ Degree } & \multirow[t]{5}{*}{2016} & \multirow[t]{5}{*}{ ASTER } & $0-2$ & 4 & $80-100$ \\
\hline & & & & & $2-6$ & 3 & $60-80$ \\
\hline & & & & & $6-20$ & 0 & $0-20$ \\
\hline & & & & & $20-30$ & 1 & $20-40$ \\
\hline & & & & & $>30$ & 2 & $40-60$ \\
\hline & \multirow[t]{5}{*}{ Aspect } & \multirow[t]{5}{*}{ Degree } & \multirow[t]{5}{*}{2016} & \multirow[t]{5}{*}{ ASTER } & $300-60$ & 0 & $0-20$ \\
\hline & & & & & $60-120$ & 2 & $40-60$ \\
\hline & & & & & $120-180$ & 4 & $80-100$ \\
\hline & & & & & $180-240$ & 3 & $60-80$ \\
\hline & & & & & $240-300$ & 1 & $20-40$ \\
\hline & \multirow[t]{5}{*}{ NDVI } & \multirow[t]{5}{*}{-1 to 1} & \multirow{5}{*}{$\begin{array}{r}1987- \\
2016\end{array}$} & \multirow{5}{*}{ Landsat 5 and 8} & $<-0.5$ & 4 & $80-100$ \\
\hline & & & & & -0.5 to -0.3 & 3 & $60-80$ \\
\hline & & & & & -0.3 to -0.2 & 2 & $40-60$ \\
\hline & & & & & -0.2 to -0.1 & 1 & $20-40$ \\
\hline & & & & & $>-0.1$ & 0 & $0-20$ \\
\hline \multirow{18}{*}{$\begin{array}{l}\text { Socioeconomic } \\
\text { stability }\end{array}$} & Illiteracy & Number of & 2009 & Ordinary kriging & $>2500$ & 4 & $80-100$ \\
\hline & & people & 2015 & based on TSI data & $2500-1500$ & 3 & $60-80$ \\
\hline & & & & & $1500-1000$ & 2 & $40-60$ \\
\hline & & & & & $1000-0$ & 1 & $20-40$ \\
\hline & & & & & $<0$ & 0 & $0-20$ \\
\hline & Population & Number of & $1990-$ & Ordinary kriging & $>550$ & 4 & $80-100$ \\
\hline & density & people $\mathrm{km}^{-2}$ & 2015 & based on TSI data & $550-350$ & 3 & $60-80$ \\
\hline & & & & & $350-150$ & 2 & $40-60$ \\
\hline & & & & & $150-50$ & 1 & $20-40$ \\
\hline & & & & & $<50$ & 0 & $0-20$ \\
\hline & Per capita & USD & $1987-$ & Ordinary kriging & $>11,000$ & 0 & $0-20$ \\
\hline & GDP & & 2011 & based on TSI data & $11,000-10,000$ & 1 & $20-40$ \\
\hline & & & & & $10,000-9000$ & 2 & $40-60$ \\
\hline & & & & & $9000-8000$ & 3 & $60-80$ \\
\hline & & & & & $<8000$ & 4 & $80-100$ \\
\hline & $\mathrm{LC}$ & $\mathrm{km}^{2}$ & $1987-$ & Landsat 5 and 8 & Decrease in $\mathrm{W}$ & 4 & $80-100$ \\
\hline & & & 2016 & & Decrease in CMTV & 3 & $60-80$ \\
\hline & & & & & Decrease in SNTV & 2 & $40-60$ \\
\hline
\end{tabular}


Table 1 (continued)

\begin{tabular}{|c|c|c|c|c|c|c|c|}
\hline Index & $\begin{array}{l}\text { Proxy } \\
\text { variable }\end{array}$ & Unit & Year & Source & $\begin{array}{l}\text { Ranges and trends of } \\
\text { spatiotemporal change }\end{array}$ & $\begin{array}{l}\text { Class } \\
\text { value }\end{array}$ & $\begin{array}{l}\text { CCVI } \\
\text { value }\end{array}$ \\
\hline & & & & & Decrease in BU & 1 & $20-40$ \\
\hline & & & & & $\begin{array}{l}\text { (No) change in BL and no changes and } \\
\text { increases in the other LCs }\end{array}$ & 0 & $0-20$ \\
\hline
\end{tabular}

LST land surface temperature, DEM digital elevation model, NDVI normalized difference vegetation index, TSI Turkish Statistical Institute, $G D P$ gross domestic product, $L C$ land cover, $W$ water body, $C M T V$ cultivated and managed terrestrial vegetation, $S N T V$ (semi-)natural terrestrial vegetation, $B U$ built-up land, $B L$ bareland

on August 26, 1987, and August 26, 2016, respectively, according to the least possible degree of cloud cover, cloud shadows, or snow cover over the study region. Since the Landsat 5 and 8 data have a different radiometric resolution of 8 and 12 bits (16 bits when processed into Level 1 data products), respectively, all the datasets were normalized over an 8-bit value range from 0 to 255 for spatiotemporal comparability performing the following linear min-max normalization:

$v^{\prime}=\frac{v-\min }{\max -\min }\left(\max _{\text {norm }}-\min _{\text {norm }}\right)+\min _{\text {norm }}$

where max and min refer to the original value range, while $\max _{\text {norm }}$ and $\min _{\text {norm }}$ are the new value range of the normalized dataset $\left(v^{\prime}\right)$.

The August LST maps were generated using the thermal infrared (TIR) bands $6(10.4-12.5 \mu \mathrm{m})$ $(120 \mathrm{~m})$ and $10(10.6-11.19 \mu \mathrm{m})(100 \mathrm{~m})$ of the Landsat 5 and 8 images, respectively, based on the following standard procedures: (1) calculation of land surface emissivity $(\varepsilon),(2)$ conversion of digital numbers $(\mathrm{DNs})$ to spectral radiance $\left(L_{\lambda}\right),(3)$ conversion of $L_{\lambda}$ to brightness temperature $\left(T_{\mathrm{b}}\right)$, and (4) conversion of $T_{\mathrm{b}}$ to LST. The Landsat TIR data were geometrically transformed to real-world coordinates and converted to $30 \mathrm{~m}$ using UTM projection and WGS84 datum.

Land surface emissivity $(\varepsilon)$ per pixel must be known in order for LST per pixel to be estimated and was extracted using NDVI values of bare soil, dense vegetation, and mixture of bare soil and vegetation; thus (Sobrino et al. 2004),

$\varepsilon=\varepsilon v^{*} P v+\varepsilon s^{*}(1-P v)+d \varepsilon$

where $\varepsilon v$ and $\varepsilon s$ are vegetation (0.99) and soil (0.97) emissivity, respectively, $P v$ is the proportion of vegetation, and $d \varepsilon$ is the surface roughness (geometric distribution effect of reflection of natural surfaces). $P v$ was derived from the NDVI values using the following equation:

$P v=\left(\frac{\mathrm{NDVI}^{-\mathrm{NDVI}_{\min }}}{\mathrm{NDVI}_{\max }-\mathrm{NDVI}_{\min }}\right)^{2}$

The NDVI values of -1 to 1 were computed using measured reflectance values in the red and near infrared (NIR) portions of the electromagnetic wavelength (Eq. 4) which correspond to bands $3(0.63-0.69 \mu \mathrm{m})$ and $4(0.64-0.67 \mu \mathrm{m})$ for Landsat 5 and bands $4(0.76-$ $0.9 \mu \mathrm{m})$ and $5(0.85-0.88 \mu \mathrm{m})$ for Landsat 8 . Red and NIR bands are the ones most affected by chlorophyll absorption and, thus, by the surface density and health of green vegetation.

$\mathrm{NDVI}=\frac{\mathrm{NIR}-\mathrm{RED}}{\mathrm{NIR}+\mathrm{RED}}$

The pixel DN values of Landsat 5 and 8 were converted to $L_{\lambda}\left(\mathrm{W} \mathrm{m}^{-2}\right.$ ster $\left.^{-1} \mu \mathrm{m}^{-1}\right)$ using the following equations (Eqs. 5 and 6) (Chander et al. 2009; Barsi et al. 2014), respectively:

$L_{\lambda}$ for Landsat 5

$$
=\left(\frac{L_{\max }-L_{\min }}{\mathrm{Qcal}_{\max }-\mathrm{Qcal}_{\min }}\right) *\left(\mathrm{Qcal}-\mathrm{Qcal}_{\min }\right)+L_{\min }
$$

where $L_{\max }$ and $L_{\max }$ are the spectral radiance scaled to $\mathrm{Qcal}_{\max }$ and $\mathrm{Qcal}_{\min }\left(\mathrm{W} \mathrm{m}^{-2} \mathrm{ster}^{-1} \mu \mathrm{m}^{-1}\right.$ ), respectively. Qcal is the quantized calibrated DN, with Qcal $_{\text {min }}$ and $\mathrm{Qcal}_{\max }$ referring to the minimum and maximum quantized DN for band 6, respectively.

$L_{\lambda}$ for Landsat $8=M_{L} * \mathrm{Qcal}+A_{L}-Q_{i}$

where $M_{L}$ is the band-specific multiplicative rescaling factor; $Q$ cal is the quantized calibrated $\mathrm{DN}$ for band 10 , $A_{L}$ is the band-specific additive rescaling factor, and $Q_{i}$ is the correction for band 10 . 
The TIR band data were converted from $L_{\lambda}$ to blackbody $T_{b}$ in degree Celsius based on the assumption that spectral emissivity of the black body $=1$ and the earth's surface is a black body as follows (Coll et al. 2010):

$T_{b}=\frac{K_{2}}{\operatorname{Ln}\left(\left(\frac{K_{1}}{L_{\lambda}}\right)+1\right)}$

where $K_{1}$ and $K_{2}$ are the calibration constants of Landsat 5 and 8.

The blackbody $T_{b}$ values were converted to LST using the following equation (Weng et al. 2004):

$$
\mathrm{LST}=\frac{T_{b}}{1+\left(\lambda^{*} \frac{T_{b}}{\rho}\right) * \operatorname{Ln} \varepsilon}-273.15
$$

where $\lambda$ is the wavelength of emitted radiance (11.45 $\mu \mathrm{m}$ for Landsat 5 and $10.895 \mu \mathrm{m}$ for Landsat 8). $\rho(0.01438 \mathrm{mK})$ is generated from $\rho=h^{*} c / \sigma$ $\left(h=\right.$ Planck's constant $=6.626 * 10^{-34} \mathrm{Js}, c=$ light velocity $=2.998 * 10^{8} \mathrm{~m} \mathrm{~s}^{-1}$ ) and $\sigma=$ Boltzmann constant $=1.38 * 10^{-23} \mathrm{~J} \mathrm{~K}^{-1}$ ). LST values in Kelvin were expressed in degree Celsius adding the absolute zero of $-273.15^{\circ} \mathrm{C}$.

Slope, aspect, and DEM data were derived from the Advanced Spaceborne Thermal Emission and Reflection Radiometer (ASTER) Global Digital Elevation Model (GDEM) (30 m resolution) acquired from http://gdex.cr.usgs.gov/gdex/. Twenty-nine-year spatiotemporal trends of LC changes were detected from the images of the two selected years identifying the following five LCs: built-up land (BU), cultivated and managed terrestrial vegetation (CMTV), (semi-)natural terrestrial vegetation (SNTV), water body (W), and bareland (BL). The multispectral image LC classification was performed using the maximum likelihood algorithm. Accuracy of the LC classifications on a per pixel basis was measured using the matrix of producer's and user's accuracies and kappa statistics. Producer's accuracy (PA) is the proportion of the pixels that are a particular category according to the reference data (the best assessment of ground condition) that are also mapped as that category (Demirkesen 2008). User's accuracy (UA) is the proportion of the pixels mapped as a particular category that are actually that category according to the reference data (Liu et al. 2007). Kappa statistic reflects the difference between actual agreement and the agreement expected by chance (Demirkesen
2008). A shapefile consisting of administrative boundaries (province and district) of the study region was obtained as ancillary data from the General Command of Mapping (http://www.hgk.msb.gov.tr/). All spatiotemporal analyses and statistics including the final composite CCVI calculation were calculated using ArcGIS 10.4 and IDRISI Selva 17.0 software.

\section{Results and discussion}

A spatiotemporally dynamic proxy of climate change impacts

Climate change impacts including increased temperature, increased atmospheric $\mathrm{CO}_{2}$ concentration, and extreme meteorological events such as droughts, flooding, and storms are already happening in a spatiotemporally dynamic way across the coastal-to-high mountain climate gradients of the study region. The regime (nature, magnitude, rate, and severity) of increased temperature and its direct and indirect influence pathways are exerting multiple interacting pressures to ecosystems such as adverse impacts on precipitation and evapotranspiration regimes, water quality and budget, ecosystem productivity, biodiversity, and stability and welfare of coupled social-ecological systems. Spatiotemporally dynamic rates of increased temperature are exerting and will continue to exert adverse impacts differently to the socioeconomic activities of the study region ranging from fisheries and tourism to agricultural sectors among others. Therefore, actual spatiotemporal changes between 1987 and 2016 in LST of August as the month with the highest temperatures recorded across the study region were selected as the most pressing composite stressor affecting climate change vulnerability that composites the trajectories of the driving forces of greenhouse gas (GHG) emissions, land-use and land-cover (LULC) changes, and feedbacks in the global climate system. Within the study region, long-term rates of spatiotemporal changes in actual August LST could as well be extrapolated as predictions for the rates of increases in near-future temperature.

The spatial variability of the August LST across the study region was higher in 1987 with the range of -5.8 to $56.3{ }^{\circ} \mathrm{C}$ than in 2016 with the range of -7.3 to $50.5^{\circ} \mathrm{C}$ (Fig. 2). However, the spatial pattern of the August LST showed considerable differences, and the areas with August LST $>40{ }^{\circ} \mathrm{C}$ were estimated to increase from 
1286 to $5963 \mathrm{~km}^{2}$ at a rate of ca. $167 \mathrm{~km}^{2}$ year ${ }^{-1}$ between 1987 and 2016 mostly in the northeastern part and the south central coast of the study region. About 0.03 and $2.3 \%$ of the study region were found to face extremely and highly vulnerable exposure due to increased LST based on the spatiotemporal trends (Fig. 3). Mean LST values in the month of August for the study region were estimated at $30 \pm 5^{\circ} \mathrm{C}$ in 1987 and $32 \pm 5{ }^{\circ} \mathrm{C}$ in 2016 . The highest August LST values in 2016 were found towards the northwestern lowlands of the Antalya province and in Konya, where NDVI values were lower. The lowest August LST values were found towards the northeastern region of the urban area. Lower LST values in 2016 were concentrated to the northwestern and western highland borders of the Antalya province.

Spatiotemporally dynamic proxies of ecological stability

Although many interacting ecological characteristics of an ecosystem determine its ecological stability, resilience (recovery speed) and resistance (inertia), ecological stability in this study was assumed to be dependent on a composite of NDVI, DEM, slope, and aspect in an area (Fig. 2). The decreasing spatiotemporal trend of the Landsat-derived NDVI values between 1987 and 2016 was assumed to be indicative of the declining quantity (density and cover) and quality (health) of biological productivity, thus further reducing the quality and functioning of life-supporting capacities of local ecosystems (Table 1). The maximum value of August NDVI estimated across the study region reached 0.98 in 1987 and 0.66 in 2016 (Fig. 2). The positive NDVI values appeared particularly low in the northern latitudes of the study region in 1987 and in 2016 (Fig. 2). The negative NDVI values indicative of water bodies, snow, and ice declined by $265 \mathrm{~km}^{2}$ from $1445 \mathrm{~km}^{2}$ in 1987 to $1180 \mathrm{~km}^{2}$ in 2016 at a rate of $9.1 \mathrm{~km}^{2}$ year ${ }^{-1}$. During the same period, the dense and densest vegetation areas with NDVI $\geq 0.5$ decreased by $283 \mathrm{~km}^{2}$ at a rate of $9.8 \mathrm{~km}^{2}$ year $^{-1}$. The highest rate of decline in NDVI between 1987 and 2016 was found to belong to the positive NDVI values $<0.2$ which corresponded to barelands at a rate of $474 \mathrm{~km}^{2}$ year ${ }^{-1}$. The areas with the NDVI values of $\geq 0.2$ to $<0.3$ and $\geq 0.3$ to $<0.5$ corresponding to bare soils and sparse vegetation such as croplands and open spaces increased at rates of 385 and $108 \mathrm{~km}^{2}$ year ${ }^{-1}$, respectively. The moderately and highly vulnerable areas due to the spatiotemporal NDVI trends were estimated to cover $0.1 \%\left(51 \mathrm{~km}^{2}\right)$ and $0.6 \%$ $\left(326 \mathrm{~km}^{2}\right)$ of the study region, respectively (Fig. 4). The minimum NDVI values in 2016 were concentrated in the northwestern and northeastern directions of the provincial border of Antalya, whereas the maximum NDVI values in 2016 were clustered along the coastal belt (Fig. 2).

Ecological stability was assumed to decrease with the increase in elevation due to higher risks of coastal inundation with projected sea level rise and increased drought sensitivity of lower (typically warmer) elevations with projected air temperature rise (Table 1). Both flat surfaces and gentle slopes were ranked the most vulnerable classes due to their ecosystem service as prime farmlands for food security, respectively, and were followed by the steepest slope range due to the highest erosion risk (Table 1). The ranges of the southfacing aspects were deemed most vulnerable as they are positively correlated with warmer temperatures because of the direct incoming solar radiation (Table 1).

Spatiotemporally dynamic proxies of socioeconomic stability

Socioeconomic stability can be considered to be the ability or responses of socioeconomic systems to resist and recover from adverse outcomes in the context of global climate change and was generally approximated using such generic indicators as awareness, welfare, and health. Multiple factors lessen socioeconomic stability of rural and urban livelihoods such as inadequate attainments of education; organization; natural, human, and man-made capitals; participatory democracy; technological advancement; economic development; distributive justice of income and power; and mitigative actions. Interaction effects of all these multiple factors can be considered to be reflected on spatiotemporal changes in major LCs. As the accuracy metrics for LC classification, PA and UA values are presented in Table 2 based on a total of 250 validation point locations ( 50 points per ach LC times five LC classes). Spatiotemporal changes

Fig. 2 Landsat 5- and 8-derived spatiotemporal dynamics of August land surface temperature (LST, ${ }^{\circ} \mathrm{C}$ ) in a 1987 and b 2016, normalized difference vegetation index (NDVI, -1 to 1 ) in c 1987 and d 2016, and land covers (LCs) in e 1987 and f 2016, respectively, and the classifications of $\mathbf{g}$ ASTER-derived digital elevation model (DEM, $\mathrm{m}$ asl) and $\mathbf{h}$ ASTER-derived slope (degree) across the study region 


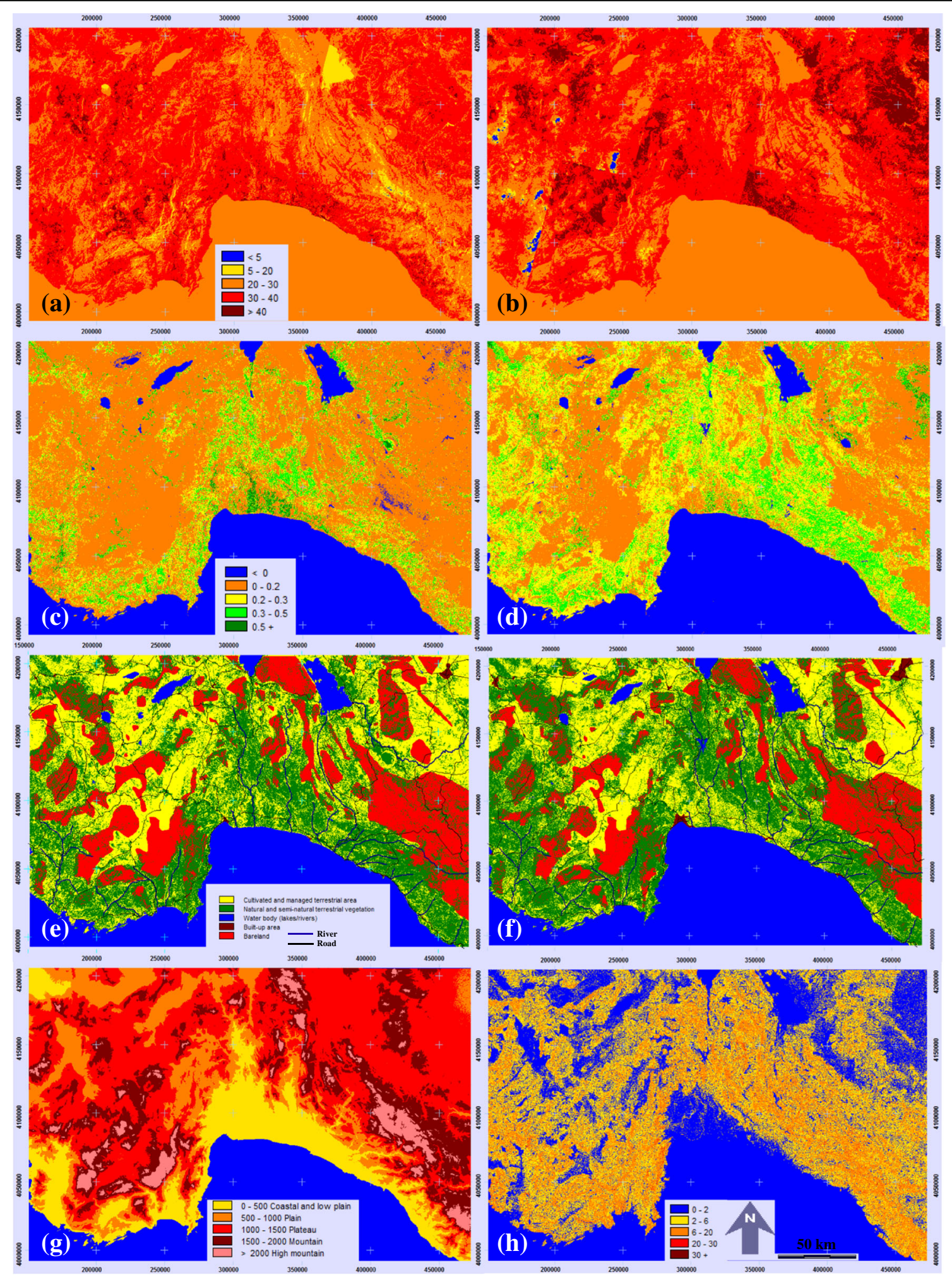




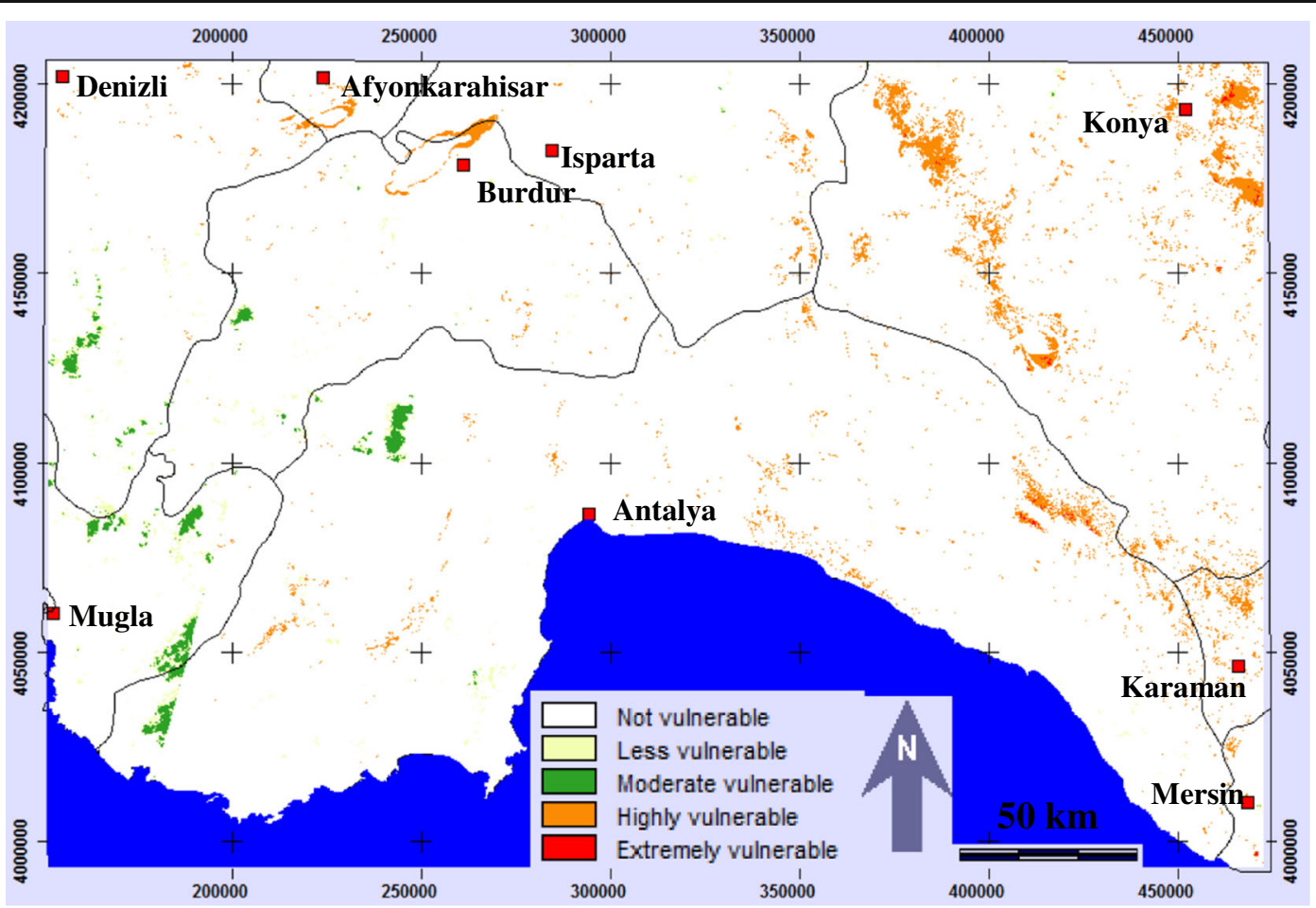

Fig. 3 Climate change vulnerability index of spatiotemporal trends of land surface temperature (LST) between 1987 Landsat 5 and 2016 Landsat 8 selected as a composite proxy for climate change impacts

in LC were detected differencing the 2016 Landsat 8 and 1987 Landsat 5 data. Net rates of changes over the study period consisted of decreasing trends of SNTV and $\mathrm{BL}$ at the rates of 155 and $92 \mathrm{~km}^{2}$ year ${ }^{-1}$ and increasing trends of CMTV, BU, and $\mathrm{W}$ at the rates of 234,10 , and $3 \mathrm{~km}^{2}$ year ${ }^{-1}$, respectively (Table 2).

The temporal decreases in the spatial extents of water body (W), cultivated and managed terrestrial vegetation (CMTV), (semi-)natural terrestrial vegetation (SNTV), and built-up land (BU) were ranked from highest to lowest in decreasing order of contribution to enhanced climate change vulnerability, due to higher risks associated with basic insecurities of water, food, ecosystem services, and housing, respectively (Table 1). The physical decline of built-up land was assumed to enhance the risk of resettlements and displacements of population along the rural-urban interface such as refugees, as well as migrants, a further human-induced pressure on destination ecosystems which in turn decreases socioeconomic stability and thus increases climate change vulnerability (Table 1). Consistent with our logic in this study, Rogers and Xue (2015) reported field evidence from a drought-prone county of China's Shanxi Province that resettlements regardless of whether or not they are climate change-induced may be a driver of maladaptation that increases more vulnerability than do nonresettled households due to constrained natural and man-made capitals. In terms of LC changes, the areas associated with the highest and second highest composite CCVI scores occupied $0.2 \%\left(114 \mathrm{~km}^{2}\right)$ (extremely vulnerable) and $4.1 \%\left(2217 \mathrm{~km}^{2}\right)$ (highly vulnerable) of our study region (Fig. 5). However, the areas ranked less vulnerable did not exist due to the lack of the physical decline of built-up land during the study period (Fig. 5).

Socioeconomic stability was assessed to decrease as a function of high population density, low per capita GDP, high illiteracy level, and decreased built-up land (Table 1) which were assumed to be associated with inadequate coping capacity and sensitive socioeconomic conditions (Fig. 5). The interpolation maps generated using ordinary kriging showed the ranges of 97 to 1289 people $\mathrm{km}^{-2}$ in 1990 and 149 to 1696 people $\mathrm{km}^{-2}$ in 2015 with the maximum value in Antalya for population density; of 910 to 2298 USD in 1987 with the maximum values in Mugla and Konya and 8335 to 15,174 USD in 2011 with the maximum value in Mugla for per capita GDP; and of 1013 to 5514 people in 2009 with the maximum values in Antalya and Denizli and 295 to 


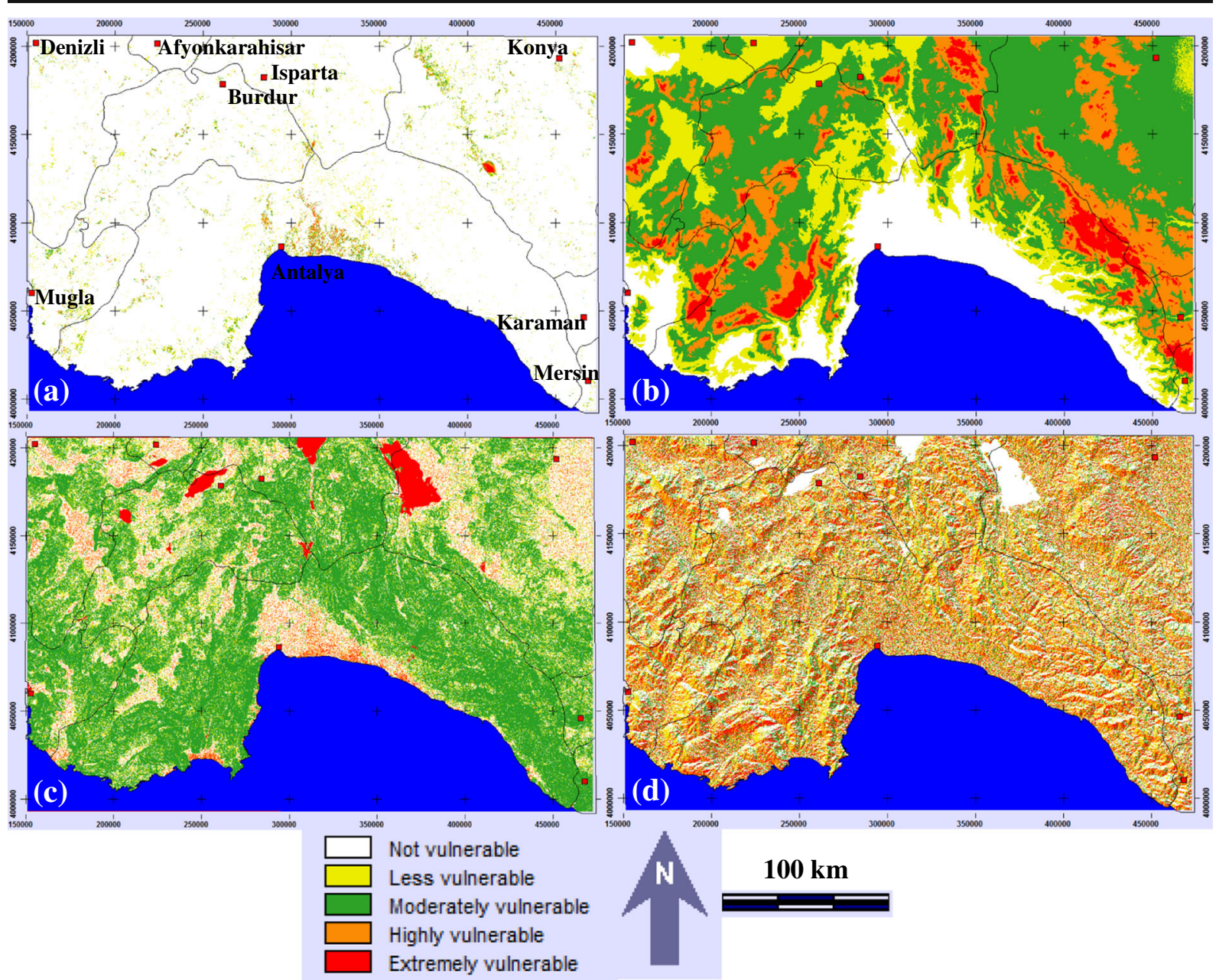

Fig. 4 Climate change vulnerability index of spatiotemporal trends of a normalized difference vegetation index (NDVI) between 1987 Landsat 5 and 2016 Landsat 8, b digital elevation

5786 in 2015 with the maximum values in Burdur for illiteracy. The moderately vulnerable-ranked areas model (DEM), c slope, and $\mathbf{d}$ aspect selected as a composite proxy for ecological stability

covered $1.1,31.3$, and $14.9 \%$, while the highly vulnerable-ranked areas amounted to 4.6, 26.4, and

Table 2 Accuracy metrics of Landsat-derived land cover (LC) classification used for this study

\begin{tabular}{lllllrr}
\hline LC & PA $(\%)$ & UA $(\%)$ & Kappa & $1987\left(\mathrm{~km}^{2}\right)$ & $2016\left(\mathrm{~km}^{2}\right)$ & Net change $\left(\mathrm{km}^{2}\right)$ \\
\hline CMTV & 85 & 85 & 85 & 19,008 & 25,780 & 6772 \\
SNTV & 90 & 90 & 90 & 20,630 & 16,139 & -4491 \\
W & 98 & 98 & 98 & 1030 & 1117 & 87 \\
BU & 95 & 95 & 95 & 132,388 & 430 & 298 \\
BL & 85 & 85 & 54,188 & 54,188 & -2666 \\
Total & & & & & 100 \\
\hline
\end{tabular}

Negative values denote a net decrease in a land cover

$P U$ producer's accuracy, UA user's accuracy, $W$ water body, CMTV cultivated and managed terrestrial vegetation, SNTV (semi-)natural terrestrial vegetation, $B U$ built-up land, $B L$ bareland 


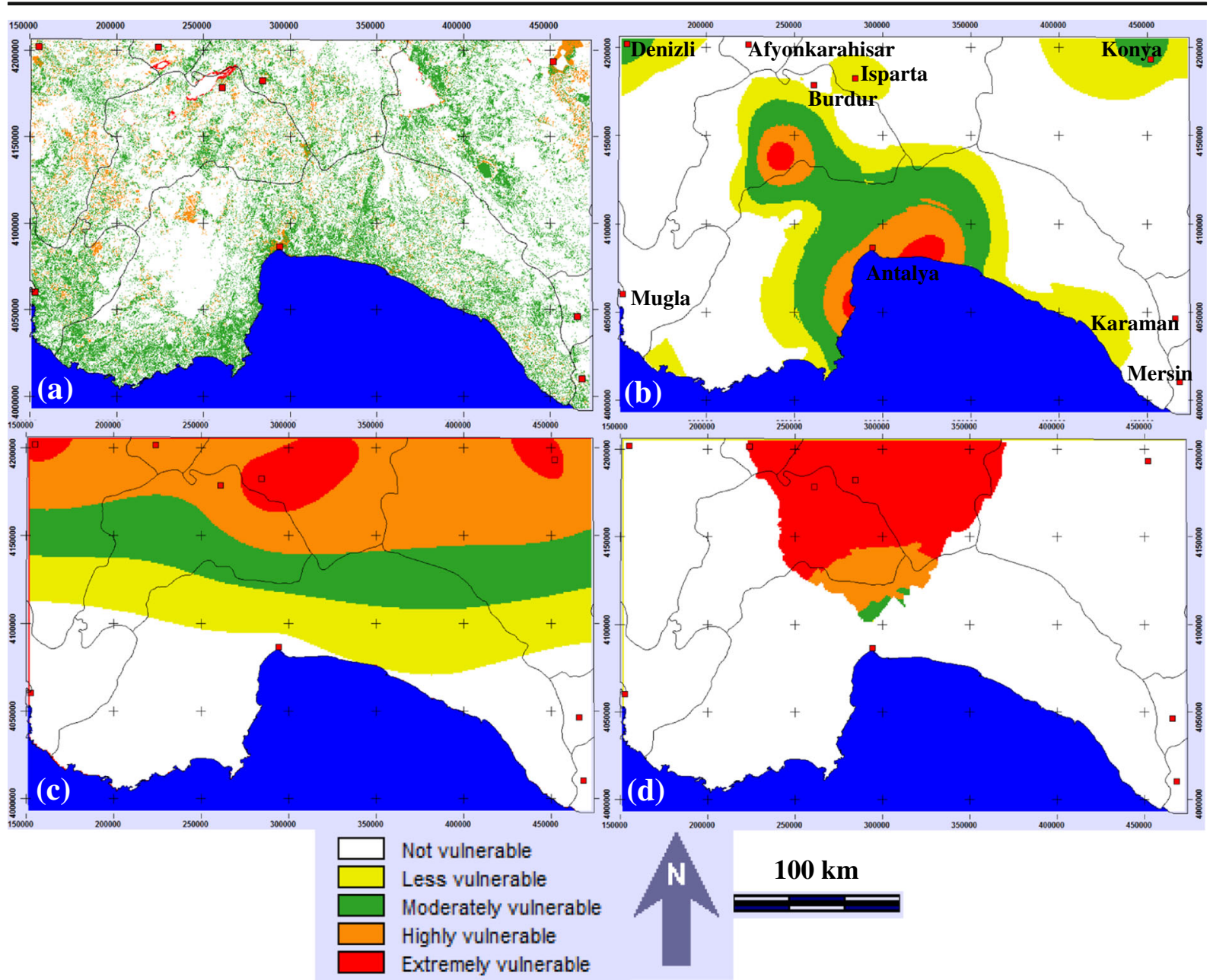

Fig. 5 Climate change vulnerability index of spatiotemporal trends of a land cover (LC) between 1987 Landsat 5 and 2016 Landsat 8, b population density between 1990 and 2015, c per

$3.0 \%$ of the study region in terms of population density, per capita GDP, and illiteracy, respectively. Liu et al. (2013) based socioeconomic vulnerability assessment in China on such data as per capita cultivated area, physicians per 1000 people, ratio between agricultural and industrial output, technologists per 1000 people, per capita savings deposits, per capita business volume of Post and Telecom Service, population density, and per capita GDP. Ahsan and Warner (2014) developed socioeconomic vulnerability index in coastal Bangladesh using such proxy variables as illiteracy, percentage of population participating in dike construction for adaptive capacity, percentage of households below poverty line, percentage of households lacking access to electricity and water for sensitivity, and percentage of households without shelter for exposure. capita gross domestic product (GDP) between 1987 and 2011, and d illiteracy between 2009 and 2015 selected as a composite proxy for socioeconomic stability

A spatiotemporally dynamic composite index of climate change vulnerability

Combining the ecological and socioeconomic proxy variables of climate change vulnerability indicated that out of $54,188 \mathrm{~km}^{2}$ of the terrestrial land assessed, no land was ranked extremely vulnerable, $0.02 \%\left(12 \mathrm{~km}^{2}\right)$ were highly vulnerable (climate change vulnerability hotspots), $11.8 \%$ $\left(6374 \mathrm{~km}^{2}\right)$ were moderately vulnerable, $65.3 \%$ $\left(35,370 \mathrm{~km}^{2}\right)$ were less vulnerable, and $22.9 \%$ $\left(12,432 \mathrm{~km}^{2}\right)$ were not vulnerable (Fig. 6). The highest composite CCVI score was found in the interior central area of the study region and was associated with the nine provinces in the following decreasing order: Isparta, Burdur, Konya, Afyonkarahisar, Antalya, Denizli, Karaman, Mersin, and Mugla. Similarly in the 


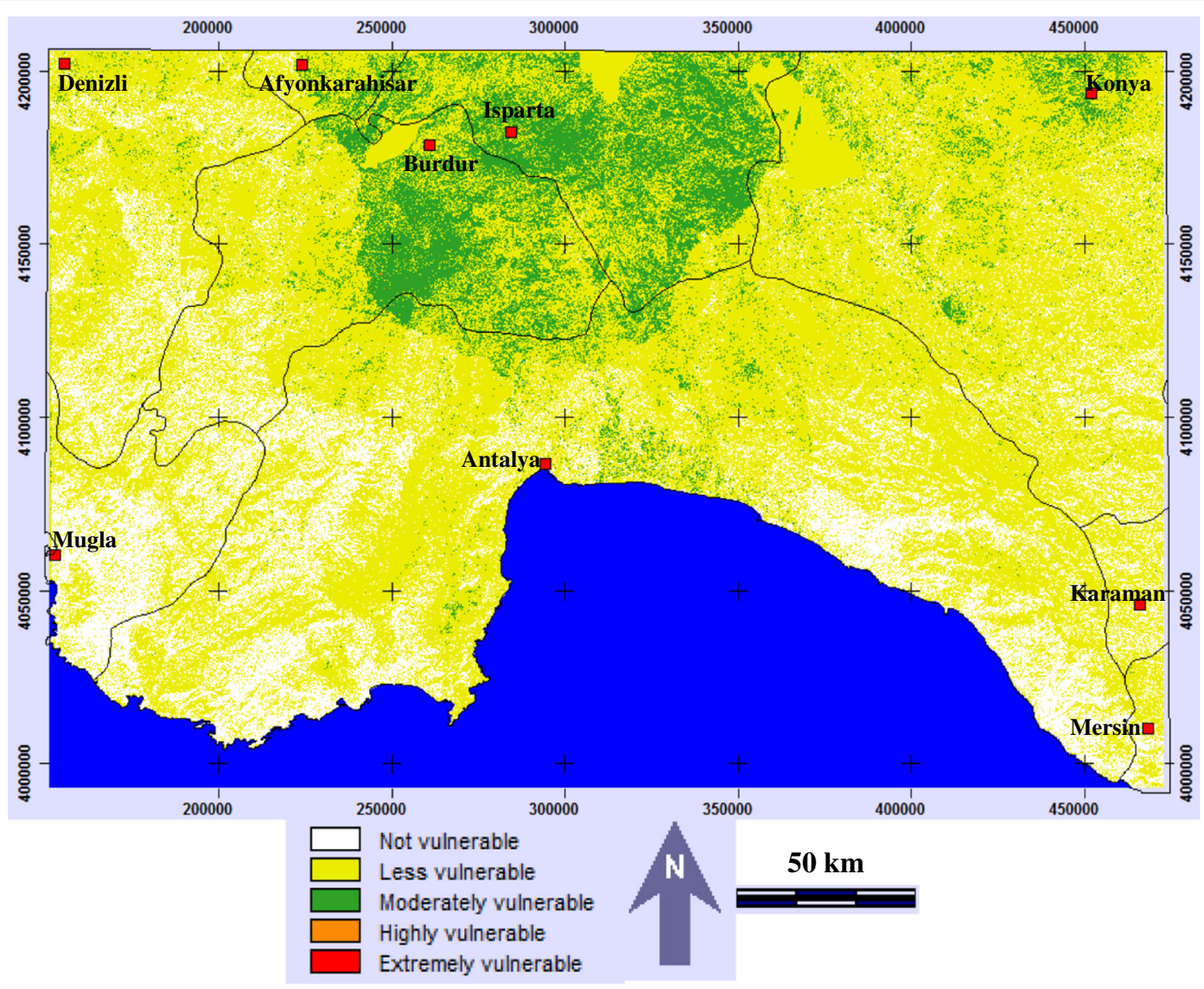

Fig. 6 Climate change vulnerability index as a spatiotemporally dynamic composite proxy for climate change impact, ecological stability, and socioeconomic stability

identification and mapping of 19 climate change hotspots in the 9 countries of the Sahel and western Africa, Hagenlocher et al. (2013) used a spatiotemporally dynamic composite indicator of cumulative climate change impact which integrated the four proxy variables of long-term seasonal temperature trends (1901-2006), long-term seasonal precipitation trends (1901-2006), long-term drought occurrences (1982-2014), and long-term major flood events (1985-2014), and the Advanced Very High Resolution Radiometer (AVHRR) images.

Our new approach was based on the net ecosystemscale effects of what has been actually observed (whether be positive and/or negative) (real-time monitoring) in the long term depending on space and time instead of using individual effects of climate change on individual components of a given ecosystem and, hence, was called composite CCVI. However, as the validity of any new approach is a function of the number, extent, and frequency of its applications across different locations and spatiotemporal scales, the approach adopted here remains to be validated elsewhere. On the other hand, there always exist uncertainties whenever quantifications, predictions, or valuations are involved. The differences in radiometric resolution, band wavelengths, and atmospheric conditions were the main source of uncertainties associated with the findings of the present study. In addition to the growing scientific knowledge about drivers of vulnerability of what ecosystems to what ecosystem (social-ecological) stressors and their spatiotemporal dynamics, local community involvement in monitoring and managing natural resources is also needed to construct, inform, and strengthen socially acceptable and spatiotemporally mitigative public policies and decision-making capacities in face of present and future effects of climate change.

\section{Conclusions}

The Mediterranean regions are considered to be climate change vulnerability hotspots. The present study 
contributes three innovative concepts to the related literature of climate change vulnerability: (1) quantifying vulnerability as a function of impact, ecological stability, and socioeconomic stability, (2) integrating the spatiotemporal trends into the composite CCVI, and (3) using LC changes as a proxy for socioeconomic stability. The adoption of a spatiotemporally dynamic CCVI such as the one used in this study across the world serves as an early warning system towards identification, prioritization, and preparedness, thus enhancing sustainability (continued self-sufficiency) of ecological-socioeconomic systems. The accuracy, precision, reliability, and cost-effectiveness of the composite CCVI to cope with climate change will increase as the availability, quality, and spatiotemporal resolution of historical time series data are improved on. This study can be scaled up or down spatiotemporally to meet specific characteristics of human-induced or natural disturbance regimes. The effectiveness of the integration of spatiotemporal trends into the composite CCVI needs to be further tested over a wider range of different regions.

Acknowledgements We would like to thank Izmir Institute of Technology and Abant Izzet Baysal University for supporting this study. We are grateful to two anonymous reviewers for their insightful and constructive comments which significantly improved an earlier version of the manuscript.

\section{References}

Ahsan, M. D. N., \& Warner, J. (2014). The socioeconomic vulnerability index: a pragmatic approach for assessing climate change led risks: a case study in the south-western coastal Bangladesh. International Journal of Disaster Risk Reduction, 8, 32-49.

Allan, R. P., \& Soden, B. J. (2008). Atmospheric warming and the amplification of precipitation extremes. Science, 321(5895), 1481-1484.

Bai, Y., Kaneko, I., Kobayashi, H., Kurihara, K., Takayabu, I., Sasaki, H., \& Murata, A. (2014). A geographic information system (GIS)-based approach to adaptation to regional climate change: a case study of Okutama-machi, Tokyo, Japan. Mitigation and Adaptation Strategies for Global Change, 19, 589-614.

Barsi, J. A., Schott, J. R., Hook, S. J., Raqueno, N. G., Markham, B. L., \& Radocinski, R. G. (2014). Landsat-8 thermal infrared sensor (TIRS) vicarious radiometric calibration. Remote Sensing, 6, 11607-11626.

Birkmann, J., Cardona, O. D., Carreno, M. L., Barbat, A. H., Pelling, M., Schneiderbauer, S., Kienberger, S., Keiler, M., Alexander, D., Zeil, P., \& Welle, T. (2013). Framing vulnerability, risk and societal responses: the MOVE framework. Natural Hazards, 67, 193-211.

Brondizio, E. S., Vogt, N., Mansur, A., Anthrony, E., Costa, S., \& Hetrick, S. (2016). A conceptual framework for analyzing deltas as coupled social ecological systems: an example from the Amazon River Delta and Estuary. Sustainability Science, 11, 591-609.

Chander, G., Markham, B. L., \& Helder, D. L. (2009). Summary of current radiometric calibration coefficients for Landsat MSS, TM, ETM+, and EO-1 ALI sensors. Remote Sensing of Environment, 113, 893-903.

Coll, C., Galve, J. M., Sánchez, J. M., \& Caselles, V. (2010). Validation of landsat-7/ETM+ thermal-band calibration and atmospheric correction with ground-based measurements. IEEE Transactions on Geoscience and Remote Sensing, 48, 547-555.

Demirkesen, A. C. (2008). Digital terrain analysis using Landsat-7 ETM+ imagery and SRTM DEM: a case study of Nevsehir province (Cappadocia), Turkey. International Journal of Remote Sensing, 29, 4173-4188.

Diffenbaugh, N. S., Scherer, M., \& Trapp, R. J. (2013). Robust increases in severe thunderstorm environments in response to greenhouse forcing. Proceedings of the National Academy of Sciences, 110, 16361-16366.

Evrendilek, F., Karakaya, N., Aslan, G., \& Ertekin, C. (2011). Using eddy covariance sensors to quantify carbon metabolism of peatlands: a case study in Turkey. Sensors, 11, 522538.

Füssel, H.-M., \& Klein, R. J. T. (2006). Climate change vulnerability assessments: an evolution of conceptual thinking. Climatic Change, 75, 301-329.

Hagenlocher, M., Lang, S., Holbling, D., Tiede, D., \& Kienberger, S. (2013). Modeling hotspots of climate change in the Sahel using object-based regionalization of multidimensional gridded datasets. IEEE Journal of Selected Topics in Applied Earth Observations and Remote Sensing, 7, 229-234.

IPCC (2001). Climate change 2001: impacts, adaptation and vulnerability. Contribution of Working Group II to the Third Assessment Report of the Intergovernmental Panel on Climate Change. Cambridge: Cambridge University Press.

IPCC (2007). Assessing key vulnerabilities and the risk from climate change. Fourth Assessment Report. Cambridge: Cambridge University Press.

IPCC (2013). Climate change 2013: the physical science basis. Contribution of Working Group I to the Fifth Assessment Report of the Intergovernmental Panel on Climate Change. Cambridge: Cambridge University Press.

Liu, C., Frazier, P., \& Kumar, L. (2007). Comparative assessment of the measures of thematic classification accuracy. Remote Sensing of Environment, 107, 606-616.

Liu, X., Wang, Y., Peng, J., Braimoh, A. K., \& Yin, H. (2013). Assessing vulnerability to drought based on exposure, sensitivity and adaptive capacity: a case study in middle inner Mangolia of China. Chinese Geographical Science, 23, 13-25.

Murthy, C. S., Yadav, M., Ahamed, J. M., Laxman, B., Prawasi, R., Sesha Sai, M. V. R., \& Hooda, R. S. (2015). A study on agricultural drought vulnerability at disaggregated level in a highly irrigated and intensely cropped state of India. Environmental Monitoring and Assessment, 187, 140.

NRC (2010). Advancing the science of climate change. National Research Council. Washington DC: The National Academies Press. 
Ostrom, E. (2009). A general framework for analyzing sustainability of social-ecological systems. Science, 325, 419-422.

Rogelj, J., Meinshausen, M., \& Knutti, R. (2012). Global warming under old and new scenarios using IPCC climate sensitivity range estimates. Nature Climate Change, 2, 248-253.

Rogers, S., \& Xue, T. (2015). Resettlement and climate change vulnerability: evidence from rural China. Global Environmental Change, 35, 62-69.

Sebesvari, Z., Renaud, F. G., Haas, S., Tessler, Z., Kloos, J., Szabo, S., Tejedor, A., \& Kuenzer, C. (2016). Vulnerability indicators for deltaic social-ecological systems: a review. Sustainability Science, 11, 1-16.

Sobrino, J. A., Jimenez-Munoz, J. C., \& Paolini, L. (2004). Land surface temperature retrieval from LANDSAT TM 5. Remote Sensing of Environment, 90, 434-440.

TSI. (2015). Turkish Statistics Institute: databases. Available at: http://www.turkstat.gov.tr/. Accessed 20 Jan 2016.
TSMS. (2013). Turkish State Meteorological Service. Available at: http://mgm.gov.tr/. Accessed 20 Jan 2016.

Wali, M. K., Evrendilek, F., West, T., Watts, S., Pant, D., Gibbs, H., \& McClead, B. (1999). Assessing terrestrial ecosystem sustainability: usefulness of regional carbon and nitrogen models. Nature \& Resources, 35, 20-33.

Weng, Q., Lu, D., \& Schubring, J. (2004). Estimation of land surface temperature-vegetation abundance relationship for urban heat island studies. Remote Sensing of Environment, 89, 467-483.

Williamson, C. E., Dodds, W., Kratz, T. K., \& Palmer, M. A. (2008). Lakes and streams as sentinels of environmental change in terrestrial and atmospheric processes. Frontiers in Ecology and the Environment, 6, 247-254.

Young, B. E., Dubois, N. S., \& Rowland, E. L. (2015). Using the climate change vulnerability index to inform adaptation planning: lessons, innovations, and next steps. Wildlife Society Bulletin, 39, 174-181. 